DE DE GRUYTER

OPEN

\title{
THE TRAP OF STEREOTYPES IN ROMANIAN COMMERCIALS INVOLVING SENIORS
}

\author{
ELENA MARIA EMANDI \\ "Ştefan cel Mare" University, Suceava, Romania
}

13, Universității St, 720229, Suceava

maria.emandi@gmail.com

\begin{abstract}
This work is intended to highlight from a semio-stylistic point of view the way in which older people are portrayed in Romanian commercials. The gender dimension is enmeshed with the interesting issue of national features in connection with such stereotypes.

Keywords: commercials, discrimination, gender role, power, semio-stylistic approach, stereotype.

\section{Introduction}

My paper is aimed at questioning the gender dimensions of commercials including seniors that have recently appeared on Romanian television. This attempt at distinguishing the national specific as far as gender stereotypes referring to elderly people are concerned was made by using semio-stylistic tools. Generally speaking, there would be no reason for
\end{abstract}


the silver generation to be negatively portrayed in commercials, since positive stereotypes and ideology concerning them reflect the standard decent Romanian view. Nevertheless, stereotypes such as forgetful seniors or over-talkative grannies can make people aware of the way society views them.

The concept of threat was introduced by Steele and Aronson and refers to the fact that the presence of stereotypes harms the performance or self-concept of a certain group. No matter whether or not the person agrees with the stereotype or believes that it might apply to them, this threat of being identified with a negative stereotype can create tension and anxiety by placing a certain category of people in the spotlight. The behaviour of the mature protagonists who appear in commercials may or may not differ from that of the younger people in terms of gender relations. The commercials may display stereotypes as far as gender roles are concerned, and the proposed analysis will confirm or deny their presence. The present study will focus on a set of commercials that have been considered representative for our purpose. This set is made up of Romanian and international advertisements that appeared on Romanian television in 2012, 2103 and the first half of 2014.

By seniors we understand people whose hair colour is grey or white, who have wrinkles on their faces or hands, or who are shown in a context that suggests the period of life when they no longer work, especially because they are officially too old to do so.

\section{Methodology of the Study}

In this section I will present the method used in the investigation, the points of view adopted being the stylistic and semiotic perspectives on how 
gender relations and stereotypes appear in the commercials taken into consideration. The results of the study will also be presented.

\subsection{Purpose of the Study}

Television advertising is a very widely consumed medium, available to all generations and reflecting existing gender stereotypes. Such stereotyped images of men and women are more or less explicit, and according to Royo et al. (2007: 381):

\footnotetext{
Women have been portrayed in a few narrowly-defined roles as unemployed or as employed in traditional women's occupations such as wife, mother or home-maker [...] They have also been represented as dependent on others, at home and depicted against a background of children $[\ldots]$ in decorative roles in relation to the product $[\ldots]$ On the other hand, men have been portrayed as independent, intelligent, hard working, professionals, objective decision-makers $[\ldots]$; as interviewers, narrators, or celebrities $[\ldots]$ and, in other locations different from home.
}

Advertised products are presented in accordance with cultural values which the viewer finds particularly acceptable. As Espinar Ruiz et al. state (2012: 111), paraphrasing from Santiso, advertisers use only

mostly spread images which are also the most retrograde and resistant to change.

It is therefore evident that although a secondary or mediated experience, television undoubtedly represents an important source of ideas about everything surrounding and involving people of all ages.

\subsection{Research Methods and Findings}


The present study takes into account commercials with seniors in major or minor roles in their complexity as audio-visual products. This type of commercial adds visual to verbal expressivity, thus permitting a more comprehensive approach.

Throughout the current study some questions designed to organize results will be answered, our aim being to verify the following hypotheses:

- women shown in Romanian commercials are discriminated against in terms of gender roles;

- there are gender stereotypes specific to the Romanian context;

- there is a direct connection between the formal features of commercials and the gender traits assigned to them by their creators.

\subsubsection{Advertising and Stereotypes}

Women and men are portrayed differently in TV commercials, these depictions being based on a number of traditional expectations. People are presented performing certain gender roles, by gender role being understood a set of activities performed with a certain degree of frequency. As Linda Brannon (2002: 160) states,

Gender stereotypes are very influential; they affect conceptualizations of women and men and establish social categories of gender. These categories represent what people think, and even when beliefs vary from reality, the beliefs can be very powerful sources in judgment of self and others [...)]Therefore, the history, structure, and function of stereotypes are important topics in understanding the impact of gender on people's lives.

\subsubsection{Semiotic Point of View}

The study of advertisements presupposes the analysis of meaning conveyed by the various signs transmitted (word, sound, visual image). 
Visual communication contains the three types of signs as designated by Charles Sanders Pierce: iconic, symbolic and indexical. Verbal, nonverbal and paraverbal signs are helpful in deciphering meanings. Possibly the most important questions in this study are those concerned with how the elements carrying semiotic meaning are related to the linguistic message and which are the symbols that are carried by the visual images.

\subsubsection{Stylistic Point of View}

A stylistic approach to commercials refers to the identification of patterns of usage both in speech and in writing. The visual imagery provided by ads embodies meanings of words and symbols that play an important part in the mental configuration of a certain society. For example, according to Claudia Rosa Acevedo (2010:173), female portrayals in advertising were categorized by Goffman into five patterns: relative size, feminine touch, function ranking, ritualization of subordination, and licensed withdrawal. Kang (1977:6) added two more: body display and independence. Such patterns have helped us in interrogating the Romanian reality as it appears in commercials involving seniors.

\subsubsection{The Gender Dimension within the Romanian Context}

\subsubsection{Current Gender Stereotypes and Their Origin}

Since gender is to be defined as a social construction, we cannot clearly determine a dichotomous unity and thus distinguish between one real masculinity and one real femininity. Therefore our study will not deal with saying which character that appears in a TV commercial spot performs as masculine or feminine. We will take broadly into consideration the traditional gender approaches and attributions. 
The roots of the contemporary gender stereotypes mirror beliefs dating back as far as the Victorian era (Brannon 2002:161). According to the Doctrine of the Two Spheres women and men have separate areas of influence. Women are conceived of as being at home taking care of children, while men are supposed to work outside the house. Another belief is the Cult of True Womanhood, which defines women in terms of piety, purity, submissiveness and domesticity. Men are viewed as naturally not so religious, inclined to sin and seduction, but through the presence of women in their lives they too become religious and pure. Thus, the dichotomy that best defines the couple man/ woman is the series passive, dependent, pure, delicate / active, independent, coarse, strong. The change in the traditional roles meant the emergence of new ideas regarding what men or women considered they should be, and thus Sex Role Strain (Gender Role Strain) appeared. The conclusion is that gender is something that people generally do rather than what people really are and that there is no masculinity or femininity, but rather masculinities and femininities.

\subsubsection{Findings: The Romanian Specificity of the Commercials Involving Seniors}

As far as the commercials that appeared on TV and involved seniors are concerned, a tendency to rely on stereotypes appears to be present, with the situations in which they appear, their words and their attitudes demonstrating that there is a tendency to attribute gender-stereotypical features to women and to men as well.

According to the type of product advertised, the commercials taken into consideration may be classified as follows: 
- Advertisements for food items: Ardealul vegetarian paté, Mars chocolate bar, Merci chocolate bar, Jacobs coffee, Poiana chocolate, Oil from Grandma (Untdelemn de la bunica) - The Family Cheese Dumplings, The Secret of Food, Timișoreana beer, Covalact (The Milky Way, Sour Cream from the Countryside, Butter from the Countryside);

- Medicine/health aids advertisements: Aspenter, Voltaren, Catena pharmacy chain (Cişmigiu Gardens, The Phone, The Slimming Shelf, Easter, The Pharmacy of the Heart), Centrofarm pharmacy chain;

- mobile communication: Cosmote;

- quality of life improvement tools: Kosmodisk, Dry Cooker, Corega, .

Two main directions were detected as far as gender relations are concerned: the commercials displayed male authority in a domain either as related to the other gender (Cosmote - The Teacher), or as related to the younger generation and to other people in general (Cosmote - The Butterfly, Cosmote - War Hero). Women appear as buyers or users (Kosmodisk, Dry Cooker, Corega), while men are more frequently presented as experts in a particular subject or as an authority on the spot due to some events in the past (Cosmote - The Butterfly, Cosmote - War Hero, Timişoreana beer 2012, Ardealul vegetarian paté).

Female authority is manifested within the family or within the domain of the home (food products). The paradigmatic choice of an elderly woman for the role of the perfect grandmother follows the well-established role of women as taking care of children. This role appears in commercials for oil and chocolate - Oil from Grandma and Merci. The counterpart of the role of perfect grandparent is represented by the perfect father figure in the Cosmote - The Butterfly commercial. Here the masculine authority 
emphasizes the gender stereotypes of male authority even in a domain that ought to belong to a woman.

As for the setting in which the action of the characters is placed one may state that more female characters appear in domestic settings (Oil from Grandma, Merci chocolate bar, Poiana chocolate, Dry Cooker, Aspenter) and fewer in outdoor locations (Catena pharmacy chain, Jacobs coffee). Masculine characters appear in outdoor locations (Covalact - The Milky Way, all the Cosmote advertisements, Catena Pharmacy - The Phone, Cişmigiu Gardens) but also at home (Catena - Easter, Aspenter). We cannot detect here a clear dichotomous distribution of feminine-indoor versus masculine-outdoor setting as there are some commercials in which women appear outside the home accompanied by men. Nevertheless, traditional gender stereotypes pervade these too, women being shown alongside protective men.

The audio background of the commercials is a means of coding features. Thus in the Merci commercial, the lyrics and the tune suggest the close relationship between the people being offered and the people offering such fine chocolate bars. Colours perform a similar task in the syntagmatic structure of the advertisements. A particular colour may appear repeatedly, in this way linking disparate paradigms with the aim of creating a continuous syntagm. As Lacey (1998) contends, colour is rich in significance, and thus it can be used with the intention of nonverbally and non-explicitly connecting ideas. The colour that appears repeatedly in the Merci commercial is red (on a white background), connoting ideas of love, devotedness, care and attention.

Beside the standardized postures of women as motherly (Merci, Jacobs coffee, Oil from Grandmother) and of men as dignified authorities 
(Timişoreana, Ardealul), we also find the humorous couple, a traditional patriarchal one, with the slogans of these commercials very often sharing semantic traits such as [+Indulgence]: "Taste the small pleasures!” (Poiana - “Gustă micile plăceri”), “Taste life to the full!”(“Gustă viaţa din plin!”).

The relatively higher presence of masculine narrators in the commercials under consideration can be related to possible connotations of trustworthiness and authority associated with the masculine voice. One cannot detect a uniquely Romanian flavour to such commercials, as the stereotypes that appear belong to the general acceptation of women as weaker and in need of protection.

As for the stylistic approach, referring to formal features as related to gender traits as assigned by specialists, we can state that the stylistic features of rapid cutting and the shorter duration of shots may generally speaking support a masculine image. This is true only in advertisements depicting elderly men as active. Other postures, when they appear mildly impaired, do not confirm this theory (Aspenter, Catena pharmacy chain.

Aronovsky and Furnham (2008:181-182) speak of women being more frequently depicted as younger than males (Voltaren gel). In this ad the older, middle-aged man appears in the company of a woman 10 or 15 years younger. This is an age disparity that connotes a harsh reality: women are expected to look youthful in appearance, while men are not exposed to such restrictions. This underlines the fact that women's status is based on their sexuality and looks, while men's value is perceived in terms of intelligence and power rather than looks.

Although studies such as that of Vernon el al. (1990:60-61) speak of an under-representation of women compared to men on television, this is 
not valid in our case, since the proportion of aged males versus females shown in commercials is quite balanced.

\section{Conclusion}

The stereotyped images of elderly men and women appear in TV commercials as comfortable and not especially offensive prototypes of masculinity and femininity, with producers following the general view and not trying to challenge such gender representations. Female presence is not significantly lower than male presence in terms of narrator or voiceover, but men more frequently appear as people of authority or experts.

In keeping with the view that appearance on TV speaks about importance or status and, consequently, that absence connotes lack of significance, mention should be made of the fact that the elderly are underrepresented in commercials and that the attitude adopted towards gender interaction reflects traditionalism.

When publicity uses a specific image, the message is that this reflects the general view of society. In the light of the commercials studied, the conclusion is that Romanian society is permeated by female role prejudice.

\section{References}

Acevedo, Claudia Rosa. 2010. "A Content Analysis of the Roles Portrayed by Women in Commercials: 1973-2008." Remark - Revista Brasileira de Marketing 9/3:170196.

Aronovsky, A and Furnham, A. 2008. "Gender Portrayals in Food Commercials at Different Times of the Day." Communications 33/2:169-190.

Brannon, Linda. 2002. "Gender Stereotypes: Masculinity and Femininity” in Psychological

Perspectives 3 [Online] Available:

http://www.ablongman.com/partners in psych/PDFs/Brannon/Brannon_ch07.pdf 
[Accessed August 15 2014].

Espinar-Ruiz Eva and González-Díaz Cristina. 2012. "Gender Portrayals in Food

Commercials: A Content Analysis of Spanish Television Advertisements.”

Observatorio Journal 6/4:109-126.

Kang, M.E. 1997. “The Portrayal of Women's Images in Magazine Advertisements:

Goffman's Gender Analysis Revisited.” Sex Roles 37/11-12:979-997.

Lacey, N.1998. Image and Representation: Key Concepts in Media Studies. London:

Macmillan Press Ltd.

Royo, M. Aldas, J. Kuster, I. and Vila, N. 2007. “Adaptation of Marketing Activities to

Cultural and Social Context: Gender Role Portrayals and Sexism in Spanish

Commercials." Sex Roles 58:379-390.

[Online]. Available: http://link.springer.com/article/10.1007/s11199-007-9341-y

[Accessed August 10 2014].

Vernon Joetta A. Williams Jr. J. Allen Phillips Terry Wilson Janet. 1990. "Media

Stereotyping: A Comparison of the Way Elderly Women and Men Are Portrayed

on Prime-Time Television." Sociology Department, Faculty Publications. Paper 5.

[Online] Available:

http://digitalcommons.unl.edu/cgi/viewcontent.cgi?article $=1004 \&$ context $=$ sociolo

gyfacpub [Accessed August 28 2014]. 